\title{
Multidrug-resistant disseminated tuberculosis in a 9-month-old infant
}

\author{
G. Sensoy ${ }^{1}$ A. Karli, ${ }^{1}$ A. Birinci, ${ }^{2}$ P.A. Uras, ${ }^{3}$ M.C. Bilgici ${ }^{4}$ and F. Karagoz ${ }^{5}$
}

\section{Introduction}

Multidrug-resistant tuberculosis (MDR) is an emerging problem in the world. It is a disease caused by strains of Mycobacterium tuberculosis that are resistant to at least isoniazid and rifampicin, the 2 most powerful firstline anti-tuberculosis drugs $(1-3)$. The World Health Organization (WHO) in 2013 reported that an estimated 12 million people worldwide had tuberculosis, with about 630000 (5.3\%) of these people having MDR tuberculosis (1).

MDR tuberculosis can affect people from all age groups. Children usually acquire primary drug-resistant tuberculosis from adults with MDR tuberculosis. However, because of the paucibacillary nature of childhood tuberculosis, a microbiological diagnosis is made in only $20-40 \%$ of cases. Drug susceptibility testing is only possible following bacteriological confirmation. Therefore, MDR tuberculosis in children is often undetected. Moreover, little is known about the clinical profile, treatment and prognosis of MDR tuberculosis in children $(2,4-7)$. Here we report the clinical picture and treatment of an infant with disseminated MDR tuberculosis.

\section{Case report}

A 9-month-old girl was admitted to our department of paediatric infectious diseases in Samsun, Turkey with complaints of swelling on the right side of her neck and a draining lesion on her right forearm over the previous 2 months. Swelling on the left side of her neck in the previous month was also observed. The patient had not recovered despite previous antibiotic therapies. She also had poor appetite and failure to gain weight. When the patient's history was further probed, the parents revealed that the child's uncle had become ill during his military service and stayed at their home during his medical examination period. The uncle had been diagnosed with tuberculosis 5 months previously. There were no other cases of tuberculosis in the family.

During physical examination, the child was in a generally good condition with a weight of $8.8 \mathrm{~kg}$ and height of 70 $\mathrm{cm}$. Multiple firm lymphadenopathies (the largest $2 \mathrm{~cm} \times 2 \mathrm{~cm}$ ) in the right cervical region and a fluctuated, hyperaemic lymph node $(2 \mathrm{~cm} \times 1.5 \mathrm{~cm})$ in the left cervical region were observed. A draining lesion on her right forearm was also found. Pulmonary auscultation was normal. She had been vaccinated with bacillus Calmette-Guérin when she was 2 months old. Tuberculin skin test, which was done after she was admitted to our hospital, was positive, with an induration of $23 \mathrm{~mm}$. HIV assay was negative. The left cervical node was drained and cultured. Direct microscopy of the lymph node exudate showed acid-fast bacilli. Nucleic acid amplification polymerase chain reaction assays of the early morning gastric aspirate and lymph node exudate were positive for M. tuberculosis. Chest Xray showed mediastinal lymphadenitis and consolidation on the right lung. Thorax computerized tomography revealed multiple lymph nodes located in the right paratracheal region, and consolidation on the middle lobe of the right lung. X-ray assay of the right arm showed an osteolytic lesion in the distal end of the right ulna, with soft tissue heterogeneity extending to the skin surrounding the bone (Figure 1). Cranial magnetic resonance imaging assay was performed to evaluate the disseminated tuberculosis. It showed multiple ring-enhancing lesions in the cerebral and cerebellar hemispheres. Moreover, cutaneous biopsy, which was performed on the right forearm, revealed granulomas with epithelioid histiocytes and Langerhans-type giant cells.

On the 7th day of hospitalization, combined anti-tuberculosis therapy with isoniazid $(10 \mathrm{mg} / \mathrm{kg} /$ day $)$, rifampicin $(15 \mathrm{mg} / \mathrm{kg} /$ day $)$, pyrazinamide $(30 \mathrm{mg} / \mathrm{kg} /$ day $)$ and ethambutol $(20 \mathrm{mg} / \mathrm{kg} /$ day $)$ was started, pending culture and drug susceptibility testing.

Drug susceptibility testing of the uncle revealed MDR tuberculosis (isoniazid, rifampicin, ethambutol and streptomycin resistant). On the 20th day of admission, therefore, rifampicin and ethambutol treatments of the girl were stopped, and anti-tuberculosis treatment was readjusted to high doses of isoniazid $(15 \mathrm{mg} / \mathrm{kg}$ once daily), pyrazinamide (30 mg/kg/day), 


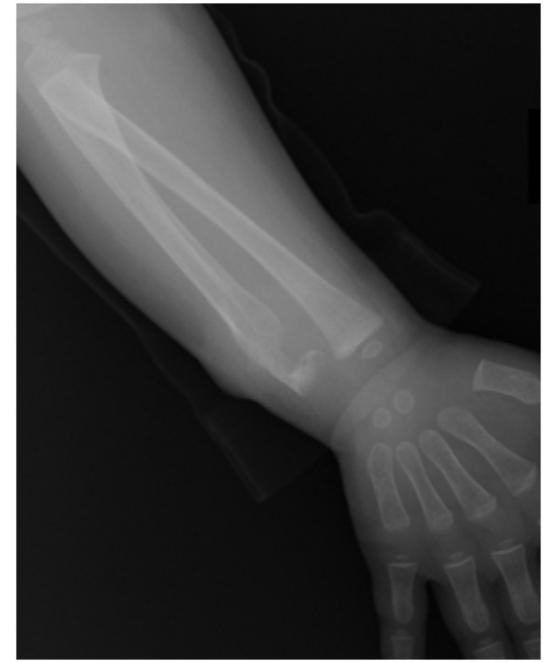

Figure 1 Chest X-ray from a case of disseminated multidrug-resistant tuberculosis in a 9-month-old infant, demonstrating an osteolytic lesion in the distal end of the right ulna with soft tissue heterogeneity extending to the skin surrounding the bone

amikacin $(15 \mathrm{mg} / \mathrm{kg} /$ day), levofloxacin $(10 \mathrm{mg} / \mathrm{kg}$ twice daily), linezolid (10 $\mathrm{mg} / \mathrm{kg}$ twice daily), cycloserine (15 $\mathrm{mg} / \mathrm{kg}$ once daily) and clofazimine (5 $\mathrm{mg} / \mathrm{kg}$ once daily) (8).

M. tuberculosis was isolated from the early morning gastric aspirate samples and lymph node exudate on the 24th day of admission. The patient's drug susceptibility testing revealed MDR tuberculosis, similar to her uncle's test.

In Turkey, tuberculosis is a notifiable disease, so we declared the patient to the public health authorities in the city of Samsun. A charitable foundation (Dispensary of the War against Tuberculosis) provided the drugs for the patient. During hospitalization, the patient recovered and gained weight. The lesion on her right forearm began to heal, and she was discharged at the end of the 2 nd month.

After discharge, directly observed therapy could not be given to the patient, but the family was very cooperative. The mother gave the drugs to the child regularly and the patient was followed up in our outpatient clinic at 1-month periods. Unfortunately, we could not monitor the serum levels of the drugs. Hearing tests were done regularly. At the end of the 3rd month of therapy, amikacin was given every other day and was stopped at the end of the 4th month. Linezolid therapy was also stopped in the 3rd month of therapy because of bone marrow suppression. Pyrazinamide was given for 9 months. The other drugs were given for 18 months. No drug side-effects were observed, except for red-brown skin coloration due to clofazimine.

A follow-up cranial magnetic resonance image scan was conducted in the $3 \mathrm{rd}$ month of therapy, and revealed that the nodular lesions in the brain had disappeared. Moreover, osteomyelitis on the ulna recovered. At the end of the therapy, the patient was in excellent health, with a weight of $13 \mathrm{~kg}$ and a height of $86 \mathrm{~cm}$.

\section{Discussion}

Young children usually contract tuberculosis through the transmission of tuberculous bacilli from a close contact in the family. In the absence of preventive therapy, infected infants younger than 12 months have up to $50 \%$ of lifetime risk of progression to disease following infection. Young children also have an increased risk of developing severe forms of the disease, such as miliary tuberculosis and tuberculosis meningitis $(9,10)$. In our patient, an uncle was the source case, and we diagnosed disseminated tuberculosis in the patient, probably due to her immature immune system. The transmission of MDR bacilli from a close contact is one of the main causes of MDR tuberculosis in children. Seddon et al. reported that the most frequent sites of extrapulmonary tuberculosis in children with MDR tuberculosis were peripheral lymph node tuberculosis (42.1\%), bone, joint or spinal tuberculosis (23.7\%), and abdominal tuberculosis (21.1\%) (4). They also found that HIV infection, malnutrition and extrapulmonary involvement were independent risk factors for death. Our patient also had lymph node, bone, cutaneous and central nervous system tuberculosis, aside from pulmonary tuberculosis. Fortunately, she recovered completely with the therapy, despite the extrapulmonary involvement.

MDR tuberculosis therapy should contain at least 4 , preferably 5 , drugs to which the organism is susceptible. Treatment recommendations for children with MDR tuberculosis are based on clinical experience in adults, and second-line drugs are generally well-tolerated by children (7). We gave our patient a high dose of isoniazid and pyrazinamide (first-line agents), amikacin (injectable agent), levofloxacin (a floroquinolone), cycloserine (oral bacteriostatic second-line agent), and clofazimine and linezolid (agents with unclear efficacy), according to WHO recommendations (8). Her clinical condition was very good in the followup visits. We did not detect hearing loss due to amikacin therapy or side-effects due to levofloxacin therapy. However, we had to stop linezolid therapy because of myelosuppression in the $3 \mathrm{rd}$ month of treatment. The other sideeffect we observed was red-brown hyperpigmentation of the skin caused by clofazimine, but we could have completed the therapy without any major complications. The patient recovered completely despite the disseminated disease.

The optimal duration of treatment for children with MDR tuberculosis is uncertain. Therapy of at least 18 months is recommended for adults. This duration may be too long for children with paucibacillary disease, but we gave an 18-month therapy considering the disseminated nature of the patient's disease.

There is a high prevalence of tuberculosis in children who live with drug-resistant tuberculosis patients, regardless of the age of the child. Therefore, it is very important that all child 
contacts of all drug-resistant patients are screened promptly for tuberculosis $(11,12)$. Preventive therapy for the contacts of MDR tuberculosis patients remains controversial, and no consensus has been reached on what regimen(s) should be used (13). However, it is generally agreed that preventive therapy is necessary for high-risk contacts, such as young children and immunocompromised individuals $(14,15)$.

This case serves as a reminder that child contacts of infectious MDR tuberculosis source cases should be closely followed up for a minimum of 2 years, and appropriate treatment should be started as soon as tuberculosis is diagnosed. Effective and safe preventive therapy regimens for drug-resistant tuberculosis are urgently needed.

\section{Funding: None.}

Competing interests: None declared.

\section{References}

1. Global tuberculosis report 2013. Geneva: World Health Organization; 2013 (http://apps.who.int/iris/bitstre am/10665/91355/1/9789241564656_eng.pdf, accessed 16 November 2015).

2. Zignol M, Sismanidis C, Falzon D, Glaziou P, Dara M, Floyd K. Multidrug-resistant tuberculosis in children: evidence from global surveillance. Eur Respir J. 2013 Sep;42(3):701-7. PMID:23222872

3. Ettehad D, Schaaf HS, Seddon JA, Cooke GS, Ford N. Treatment outcomes for children with multidrug-resistant tuberculosis: a systematic review and meta-analysis. Lancet Infect Dis. 2012 Jun;12(6):449-56. PMID:22373593

4. Seddon JA, Hesseling AC, Willemse M, Donald PR, Schaaf HS. Culture-confirmed multidrug-resistant tuberculosis in children: clinical features, treatment, and outcome. Clin Infect Dis. 2012 Jan 15;54(2):157-66. PMID:22052896

5. Schaaf HS, Garcia-Prats AJ, Hesseling AC, Seddon JA. Managing multidrug-resistant tuberculosis in children: review of recent developments. Curr Opin Infect Dis. 2014 Jun;27(3):211-9. PMID:24751893

6. Jenkins HE, Tolman AW, Yuen CM, Parr JB, Keshavjee S, PérezVélez CM, et al. Incidence of multidrug-resistant tuberculosis disease in children: systematic review and global estimates. Lancet. 2014 May 3;383(9928):1572-9. PMID:24671080

7. Feja K, McNelley E, Tran CS, Burzynski J, Saiman L. Management of pediatric multidrug-resistant tuberculosis and latent tuberculosis infections in New York City from 1995 to 2003. Pediatr Infect Dis J. 2008 Oct;27(10):907-12. PMID:18756183

8. Seddon JA, Hesseling AC, Marais BJ, Mcllleron H, Peloquin CA, Donald PR, et al. Paediatric use of second-line anti-tuberculo- sis agents: a review. Tuberculosis (Edinb). 2012 Jan;92(1):9-17. PMID:22118883

9. Seddon JA, Hesseling AC, Godfrey-Faussett P, Fielding K, Schaaf HS. Risk factors for infection and disease in child contacts of multidrug-resistant tuberculosis: a cross-sectional study. BMC Infect Dis. 2013;13:392. PMID:23977834

10. Seddon JA, Hesseling AC, Finlayson H, Fielding K, Cox H, Hughes J, et al. Preventive therapy for child contacts of multidrug-resistant tuberculosis: a prospective cohort study. Clin Infect Dis. 2013 Dec;57(12):1676-84. PMID:24065321

11. Amanullah F, Ashfaq M, Khowaja S, Parekh A, Salahuddin N, Lotia-Farrukh I, et al. High tuberculosis prevalence in children exposed at home to drug-resistant tuberculosis. Int J Tuberc Lung Dis. 2014 May;18(5):520-7. PMID:24903786

12. Becerra MC, Franke MF, Appleton SC, Joseph JK, Bayona J, Atwood SS, et al. Tuberculosis in children exposed at home to multidrug-resistant tuberculosis. Pediatr Infect Dis J. 2013 Feb;32(2):115-9. PMID:22926210

13. Turkova A, Welch SB, Paton JY, Riordan A, Williams B, Patel SV, et al. Management of paediatric tuberculosis in leading UK centres: unveiling consensus and discrepancies. Int J Tuberc Lung Dis. 2014 Sep;18(9):1047-56. PMID:25189551

14. Schaaf HS, Marais BJ. Management of multidrug-resistant tuberculosis in children: a survival guide for paediatricians. Paediatr Respir Rev. 2011 Mar;12(1):31-8. PMID:21172673

15. Seddon JA, Godfrey-Faussett P, Hesseling AC, Gie RP, Beyers N, Schaaf HS. Management of children exposed to multidrugresistant Mycobacterium tuberculosis. Lancet Infect Dis. 2012 Jun;12(6):469-79. PMID:22373591 